graph should be. It is succinct, readable and reliable. The subject of the megaloblastic anaemias is one in which rapid advances have been made in recent years and there was a widely felt need for an authoritative summary of the present day position. This little book fills that need admirably. The authors discuss all the forms of the megaloblastic anaemias and have skilfully outlined the position of present-day research in this field. The book will be of value not only to the practising haematologist to whom it will supply a useful summary, but also to the general physician who wants to clarify his ideas in a difficult subject.

\section{THE BRITISH CONTRIBUTION TO MEDICINE}

By Dr. J. Jaramillo-Arango. Pp. xii +220 , with 45 illustrations. Edinburgh: E. \& S. Livingstone, Ltd. 1953. 25 s.

The author of this interesting book, Dr. Jaime Jaramillo-Arango, was Ambassador of the Republic of Columbia to Great Britain during the Second World War. Previously he had practised as a surgeon in Columbia and was Rector of the National Faculty of Medicine of Bogota. $\mathrm{He}$ is therefore a highly competent foreign observer of British Medicine whose knowledge of Great Britain has clearly made him very sympathetic to the aims and ideals of British Medicine.

The book opens with a historical survey of eminent British work in medicine and then, in succeeding chapters, proceeds to consider in detail six main subjects where British contributions have been particularly important. These are: the vaccine treatment of enteric fevers, the discovery of penicillin, the use of other antibiotics, the treatment of malaria, the discovery of the vitamins, and cancer research. The author sketches in the historical background of all these subjects and then describes in some detail the more recent advances in our knowledge of them. Although the main purpose of the book is to emphasise the importance of British contributions to medical knowledge, the author also provides a fair statement of the contributions made by workers in other countries. His style is attractive and the book is eminently readable.

\section{ULCERATIVE COLITIS AND ITS SURGICAL TREATMENT}

By Bryan N. Brooke, M.Chir., F.R.C.S. Pp. ix +147 , with 89 illustrations, many in colour. Edinburgh: E. \& S. Livingstone, Ltd. 1954. 37s. 6d.

The surgery of ulcerative colitis has undergone considerable changes in the last few years, and a monograph on the subject taking stock of these developments is certainly timely. Mr. Brooke brings to the task of writing such a work a very considerable personal experience of the disease and its surgical,treatment. To this he has allied a thorough survey of the relevant literature and a literary craftsmanship of a high order, so that the resulting volume is both comprehensive and eminently readable.

The evolution of surgical methods in the treatment of colitis is surveyed from appendicostomy to the modern combined ileostomy and colectomy or proctocolectomy. The technique of the latter operations is described in detail and the excellent results obtained by the author and by other workers are reported in full. It is clear that these apparently formidable procedures can now be carried out with a low mortality even in critically ill patients suffering from colonic perforation or massive haemorrhage. Conservative methods of colectomy with preservation of the rectum and anal sphincters with ileorectal or ileo-anal anastomosis are categorically condemned. Some surgeons may wonder if this condemnation is not too sweeping, for cases are occasionally encountered where the rectum is substantially normal and colectomy with ileo-rectal anastomosis gives an excellent functional result, at any rate for some years, but few will dispute that ileostomy must remain one of the keystones in treatment for most patients proceeding to surgery. One of the best sections in the book is, appropriately, that dealing with the construction and subsequent care of an ileostomy. The advantages of adherent ileostomy appliances of the Rutzen type are rightly stressed but attention is drawn to some of their imperfections.

The author has taken the opportunity presented by the pathological material derived from hiso colectomies and proctocolectomies to review the clinico-pathological features of ulcerative colitis. In describing the various morbid changes that may be encountered he attempts to classify cases of colitis into four quite distinct pathological entities; proctosigmoiditis, true ulcerative colitis, ileocolitis and Crohn's disease. It cannot be said that the evidence that these are separate conditions is at all convincing. Ileocolitis seems to figure much more largely in the author's experience than in that of most other gastro-enterologists; one effect of this book, however, will be to direct attention to the lower ileum in patients with colitis:

The monograph is lavishly illustrated, many of the figures being in colour. Most of the illustrations are excellent, but a few of the coloured plates of specimens and operative views, which must have added considerably to the expense of the book, are of very doubtful value, for they remain virtually unintelligible even after reading the legends.

Altogether this is an excellent work which should be most helpful to surgeons and physicians called upon to treat patients suffering from ulcerative colitis, even if they do not agree with all that they read in it.

$$
\text { J.C.G. }
$$

\section{PEPTIC ULCER}

By C. F. W. Illingworth, C.B.E., M.D., Ch.M., F.R.C.S.E., F.R.F.P.S. Pp. vii +287 , with 89 illustrations, some in colour. Edinburgh: E. \& S. Livingstone, Ltd., 1953. 42s.

There is nothing cut and dried about our 